Cross-sectional study

\section{Determination of a single, universal threshold for caesarean section rate is not the way forward \\ 10.1136/ebmed-2016-110393}

\section{Ana Pilar Betrán, ${ }^{1}$ Jun Zhang, ${ }^{2}$ Maria Regina Torloni, ${ }^{3}$ A Metin Gülmezoglu ${ }^{1}$}

${ }^{1}$ Department of Reproductive Health and Research, World Health Organization, Geneva, Switzerland; ${ }^{2}$ Shanghai Jiao Tong University School of Medicine, Shanghai, China; ${ }^{3}$ São Paulo Federal University, Evidence Based Healthcare Post Graduate Program, São Paulo, Brazil

Correspondence to: Dr Ana Pilar Betrán, Department of Reproductive Health and Research, World Health Organization, 20, Avenue Appia, 1211 Geneva 27, Switzerland; betrana@who.int

Commentary on: Molina G, Weiser TG, Lipsitz SR, et al. Relationship between cesarean delivery rate and maternal and neonatal mortality. JAMA 2015;314:2263-70.

\section{Context}

Over the past decades, the steady rise in caesarean section rates worldwide has led to increased research, debate and concern among clinicians, scientists, policymakers and governments, with sustained questions: What is the appropriate caesarean section rate? What is the rate or range that achieves best maternal and perinatal outcomes? Several ecological studies have been conducted to answer these questions at population level. ${ }^{1}$ In April 2015, WHO released a Statement on Caesarean Section Rates ${ }^{2}{ }^{3}$ summarising the evidence on population-level caesarean section rates versus maternal/perinatal outcomes, replacing the earlier 1985 WHO Statement, which had suggested that rates higher than $10-15 \%$ were not justifiable. ${ }^{4}$

\section{Methods}

This study was a cross-sectional analysis of nationally representative data evaluating the ecological relationship between caesarean section rates, and maternal and neonatal mortality. The authors used the most recent data available from the years 2005 through 2012 for each country. Data were obtained from multiple sources, which have been virtually the same sources used in all other previous ecological analysis published to date, and are internationally recognised and accepted for this type of analysis. Coverage was high: for caesarean section, data from 194 countries were included in the analysis, of which 52 were observed, 118 extrapolated for 2012 and 22 imputed using a predictive model. For maternal and neonatal mortality, data were available for 181 and 191 countries, respectively. This analysis used spline regression models, which are flexible models that include an effort to adjust for confounding factors that may explain the association found.

\section{Findings}

The authors concluded that national caesarean delivery rates up to approximately 19\% are associated with lowered maternal and neonatal mortality (19.1\% for maternal mortality and $19.4 \%$ for neonatal mortality). CIs (95\%) were 16.3 to 21.9 for maternal mortality and 18.6 to 20.3 for neonatal mortality. Above this threshold, increasing caesarean section rates are not associated with reductions in these mortalities.

\section{Commentary}

The threshold for the optimal rate of caesarean deliveries proposed in this analysis is higher than any other found in the literature attempting a response to the same question, to date. ${ }^{1}$ This threshold is also notably higher than that stemming from the latest published analysis forming the basis for the 2015
WHO statement. The latter found that caesarean rates higher than $10 \%$ were not associated with decreases in maternal and neonatal mortality. It used a longitudinal approach and equally flexible two-level mixed models (factorial polynomial regression models). ${ }^{5}$ However, the authors do not discuss the aforementioned systematic review of the literature ${ }^{1}$ nor the WHO analysis. ${ }^{5}$

Nonetheless, all ecological analyses have limitations that are acknowledged by the authors and limit their interpretation. First, correlation does not mean causation, and despite efforts to perform adjustments, additional residual confounders are likely to be affecting this ecological association. To this end, a longitudinal approach has an advantage over cross-sectional analysis in controlling for intrinsic confounding and in making causal inference. A second and more important limitation is that mortality is normally the only outcome considered in the analyses. Maternal and newborn morbidity (eg, obstetric fistula, birth asphyxia), or psychological and social well-being (eg, maternalinfant relationship, women's psychological health or ability to successfully initiate breast feeding) as well as long-term paediatric outcomes should be considered when estimating a rate that would achieve optimal outcomes. However, since there are practically no morbidity data at the population level, it has not been possible to assess the ecological relationship between caesarean section and these other outcomes.

\section{Implications for practice}

The WHO, in its recent 2015 Statement on Caesarean Section Rates, emphasised that the focus should be to provide caesarean sections to all women in need rather than striving to achieve any specific rate at the population level. The Statement also consolidates the shift in the focus of attention from the search for an optimal caesarean section rate that provides little basis for action, to a practical and feasible proposal: the use of the classification as a standard system to monitor and compare caesarean section rates at the facility or other levels. Producing information in a standardised, reproducible and reliable manner would shine a light into the process of deciding what the appropriate caesarean section rate in a particular setting may be. This caesarean section rate will vary for different facilities with different resources, medical, obstetrical and sociocultural conditions, but it will represent the rate or range that achieves best maternal and perinatal outcomes at each particular facility.

Competing interests All the authors were involved in the 2015 WHO Statement on Caesarean Section Rates and are coauthors of the syst6ematics review and analyses that formed the basis for the Statement and that are cited in the Commentary.

Provenance and peer review Commissioned; internally peer reviewed.

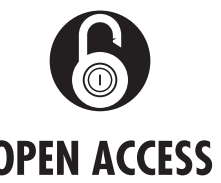

Open Access This is an Open Access article distributed in accordance with the Creative Commons Attribution Non Commercial (CC BY-NC 4.0) license, which permits others to distribute, remix, adapt, build upon this work non-commercially, and license their derivative works on different terms, provided the original work is properly cited and the use is noncommercial. See: http://creativecommons.org/licenses/by-nc/4.0/

\section{References}

1. Betran AP, Torloni MR, Zhang J, et al. What is the optimal rate of caesarean section at population level? A systematic review of ecologic studies. Reprod Health 2015;12:57.

2. World Health Organization. WHO Statement on Caesarean Section Rates. Geneva: World Health Organization, 2015. (WHO/RHR/15.02).

3. Betrán AP, Torloni MR, Zhang J, et al. WHO Working Group on Caesarean Section. Commentary: WHO Statement on Caesarean Section Rates. BJOG 2015. Published Online First: 22 Jul 2015. doi: 10.1111/1471-0528.13526

4. WHO. Appropriate technology for birth. Lancet 1985;2:436-7.

5. Ye J, Zhang J, Mikolajczyk R, et al. Association between rates of caesarean section and maternal and neonatal mortality in the 21st century: a worldwide population-based ecological study with longitudinal data. BJOG 2015. Published Online First: 24 Aug 2015. doi: 10.1111/1471-0528.13592 